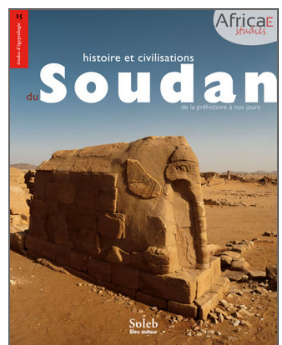

Olivier Cabon (dir.)

Histoire et civilisation du Soudan

De la préhistoire à nos jours

\title{
2. Les peuples pasteurs
}

Les cultures protohistoriques : Groupe A, Pré-Kerma. 3 500-2 500 av. J.-C.

\section{Claude Rilly}

DOI : $10.4000 /$ books.africae. 2792

Éditeur: Africae, Soleb, Bleu autour

Lieu d'édition : Paris, Khartoum

Année d'édition : 2017

Date de mise en ligne : 17 janvier 2022

Collection : Africae Studies

EAN électronique : 9782493207074

\section{OpenEdition}

\section{Books}

http://books.openedition.org

\section{Référence électronique}

RILLY, Claude. 2. Les peuples pasteurs : Les cultures protohistoriques : Groupe A, Pré-Kerma. 3 500-2 500

av. J.-C In : Histoire et civilisation du Soudan : De la préhistoire à nos jours [en ligne]. Paris, Khartoum Africae, 2017 (généré le 28 janvier 2022). Disponible sur Internet : <http://books.openedition.org/ africae/2792>. ISBN : 9782493207074 . DOI : https://doi.org/10.4000/books.africae.2792. 


\title{
les peuples pasteurs
}

\section{les cultures protohistoriques:}

\author{
Groupe A, Pré-Kerma
}

3500-2500 av. J.-C. 
L'histoire est souvent considérée comme un vaste réservoir de précédents où l'on pioche pour éclairer le présent ou prédire l'avenir. C'est en bonne partie ce qui explique la vogue dont jouissent actuellement les études historiques centrées sur les changements climatiques, grande préoccupation de notre temps. Ces modifications du milieu sont volontiers tenues pour responsables aussi bien de la fin de l'Ancien Empire en Égypte que de celle de l'Ancien Régime en France. Quoi que l'on pense des excès de cette mode, force est de constater au moins que les théories environnementales sont tout à fait pertinentes pour expliquer l'établissement des premières civilisations dans la vallée du Nil.

L'Égypte, située plus au nord, fut touchée en premier par la redescente vers l'équateur des pluies estivales. Dès la fin du sixième millénaire, le désert Libyque entama un lent processus de dessiccation, obligeant les populations qui y vivaient de l'élevage à se rapprocher du Nil. Les habitants d'autres régions limitrophes de la vallée, frappés par le même phénomène, vinrent s'ajouter aux récents occupants des rives du fleuve. Cette agglomération de nouveaux venus le long du Nil mena à la création de principautés protohistoriques au quatrième millénaire, puis à leur unification progressive en un seul royaume par les premiers pharaons vers 3000 av. J.-C.

Plus au sud, au Soudan, les mêmes causes entraînèrent les mêmes effets, avec un décalage de plusieurs siècles dû à la différence de latitude. Ce n'est qu'à partir du quatrième millénaire que le NordKordofan commença à s'assécher. Les affluents du Nil qui le traversaient comme le Wadi el-Melik ou le Wadi Howar n'eurent alors plus suffisamment de débit pour atteindre le fleuve. Selon une constante de la préhistoire soudanaise relevée par Matthieu Honegger, les déplacements de population se sont faits selon un axe vertical (nord-sud ou sud-nord) durant les périodes humides et selon un axe transversal (ouest-est) durant les périodes sèches. La période protohistorique au Soudan correspond à la fin de la dernière période humide. Les deux cultures attestées alors en Nubie, le Groupe A au nord et le Pré-Kerma au sud, appartiennent à des populations où l'élevage est prédominant et implique des déplacements annuels le long du fleuve et entre le Nil et les zones de pâture encore disponibles, souvent réduites à l'état de marécages. La vie de ces pasteurs est rythmée par ces voyages entre les campements saisonniers et les premiers villages permanents, où se font les échanges et les cérémonies importantes, y compris les inhumations. 


\section{Le Groupe A}

le Soudan

50

des origines

à la chute

du sultanat

Fung

Lorsque l'archéologue américain George Reisner entreprit, sous l'égide de l'université Harvard et du Museum of Fine Arts de Boston, les premières fouilles d'ampleur au Soudan entre 1907 et 1917, il découvrit au nord de la Nubie les vestiges de cultures indigènes antérieures à la colonisation égyptienne, qu'il classa chronologiquement en trois groupes A, B et C. Il s'avéra par la suite que le Groupe B était une composante ancienne du Groupe A et non une culture intermédiaire. Les sites du Groupe A se situent majoritairement en Nubie égyptienne, au nord de l'actuelle frontière avec le Soudan. Lors des fouilles de sauvetage de la Nubie organisées par l'Unesco durant la construction du barrage d'Assouan, notre connaissance de cette culture s'est accrue considérablement puisque son territoire entre première et deuxième cataracte s'étendait exclusivement sur la portion de la vallée submergée à partir de 1964 par le lac de retenue. En revanche, la quasi-totalité des sites est désormais inaccessible et les progrès enregistrés dans la compréhension du Groupe $\mathrm{A}$ sont depuis cinquante ans limités à l'analyse et à l'interprétation du matériel et des données archéologiques issus des fouilles passées.

La culture du Groupe A est attestée entre 3700 et 2800 av. J.-C. et correspond donc aux périodes de formation de l'État pharaonique (époques Nagada I-III et de la dynastie 0 à la II ${ }^{e}$ dynastie). Elle s'étend de Kubbaniya, à une dizaine de kilomètres au nord d'Assouan, jusqu'à Saras, $30 \mathrm{~km}$ au sud de Wadi Halfa. Toutefois, l'occupation de l'ensemble de ce territoire n'est effective qu'à l'époque dite "moyenne» ou "classique». La période initiale, dite "ancienne» (3700-3250 av. J.-C.), comporte en effet des sites localisés très au nord, proches de la première cataracte (Khor Bahan, Debod, Dakka), alors que le sud est encore occupé par une culture locale dite "abkienne" (d'après le site d'Abka) qui s'apparente au Néolithique final de Nubie. Lors de la période "moyenne» (3250-3150 av. J.-C.), les sites se multiplient autour de trois régions principales, Assouan au nord, Dakka et Sayala au centre et Wadi Halfa au sud, cette dernière ayant sans doute inclus les éléments tardifs de la culture abkienne. À la période finale (3150-2 800 av. J.-C.), les sites du nord disparaissent, ceux du milieu autour de Sayala se maintiennent, alors que le sud connaît une importante floraison autour de centres de pouvoir comme Qustul et Gammai, où ont été exhumées des tombes véritablement princières. Cette répartition spatio-temporelle est évidemment à mettre en relation avec la constitution progressive de l'État égyptien dont la politique expansionniste a chassé les populations du Groupe A de plus en plus au sud, tout en entretenant avec elles, au fur et à mesure que la société pharaonique se constituait, des relations commerciales croissantes qui ont leur part dans le luxe des enterrements de la phase finale. 
Les populations du Groupe A ont apparemment connu une économie diversifiée autour de l'élevage, de l'agriculture et des échanges avec l'Égypte. La plupart des 75 agglomérations fouillées par les archéologues étaient constituée d'habitations précaires, construites en branches et en roseaux, qui évoquent plutôt des campements saisonniers liés à l'activité pastorale que de véritables villages. On suppose, d'après des poteries typiques du Groupe A retrouvées sur ces sites, que les transhumances des troupeaux allaient jusqu’à des zones occidentales aujourd'hui quasi arides comme le Wadi Shaw, les oasis de Laqiya et même de lointains points d'eau comme Bir Sahara, distant de plus de $250 \mathrm{~km}$ du fleuve. L'importance économique du bétail se double, selon une tradition qui, au Soudan, remonte au Mésolithique, d'une valeur symbolique et peut-être religieuse, comme en témoignent les enterrements rituels de bovins dans les sites du Groupe A, particulièrement à Qustul. C'est également de cette période que datent, dans des grottes situées près de Sayala, Korosko et Serra-Ouest, des représentations rupestres de troupeaux, associées à celles de la grande faune sauvage africaine.

Lagriculture est pauvrement documentée, mais l'accroissement important de la population du Groupe A dans les phases moyenne et finale ne peut s'expliquer par les seuls moyens de subsistance hérités du Néolithique, à savoir l'élevage et la chasse, complétés par les poissons et coquillages du Nil dont la consommation était, semble-t-il, déjà marginale. La présence de nombreuses jarres à grains dans les tombes et de centaines de fosses de stockage en bordure de certaines agglomérations indique que la récolte de céréales et, peut-être aussi, leur importation depuis l'Égypte jouaient un rôle important dans l'économie de ces populations.

Les échanges avec l'Égypte contribuent à la richesse du Groupe A. Dès la période ancienne, les sépultures comportent une importante proportion d'objets de facture égyptienne (culture de Nagada I-II). La poterie est prédominante, depuis les larges jarres à grains, à bière ou à vin, jusqu'aux bols pansus (souvent décorés ensuite de motifs locaux), mais l'on trouve aussi des palettes de schiste, des vases de pierre, des peignes, des bijoux et des outils de cuivre. L'absence de ces biens d'importation parmi les cultures situées plus en amont du fleuve au quatrième millénaire laisse penser que le Groupe A avait fait des échanges avec les Égyptiens de la période prédynastique une sorte de monopole, qui ne sera brisé qu'à partir de la phase finale, vers 3000 av. J.-C. Ces produits étaient troqués contre des matières premières issues des savanes africaines, alors situées bien plus au nord qu'aujourd'hui: ivoire d'éléphant, bois d'ébène, peaux de félins, œufs d'autruches et, à côté de ces matériaux acquis depuis le sud, des bovins sur pied et des productions céramiques locales dont on a retrouvé des exemplaires dans certaines tombes égyptiennes. On possède 
quelques indices ténus qui laissent supposer que, si elle n'exploitait pas elle-même les mines d'or du Wadi Allaqi et du Wadi Gabgaba, situées à l'est de la Basse-Nubie, la population du Groupe $A$ se procurait auprès des nomades du désert Arabique le métal précieux pour l'inclure dans ses échanges avec l'Égypte.

Les relations du Groupe A et de l'Égypte toute proche sont de plus en plus interprétées, non en termes d'influence, mais de proximité culturelle, les deux sociétés étant issues d'une sorte de «Néolithique des déserts», selon le terme d'Hélène Delattre. Jusque dans le domaine funéraire, la disposition du corps en position contractée sur le côté gauche, tête tournée vers le sud, au fond d'une fosse ovale, ne diffère guère des inhumations contemporaines de Haute-Égypte. Mais ces caractéristiques s'inscrivent d'autre part dans la continuité de la tradition néolithique de Nubie et il n'est pas sûr que l'influence se soit exercée ici du nord vers le sud. À l'époque finale, dans les cimetières de l'élite locale, apparaissent des objets qui semblent copiés de l'art égyptien des premières dynasties. Ainsi, un encensoir de pierre, d'une forme inconnue en Égypte mais attestée en Nubie, a été découvert dans la tombe L24 de Qustul. Il est gravé d'une façade de palais et de trois bateaux où l'on distingue la figure d'un roi coiffé de la haute couronne blanche pharaonique. De tels éléments ont conduit certains chercheurs à supposer que le Groupe A était une culture égyptienne excentrée. Pourtant, sa «nubianité» ne fait pas vraiment de doute. Il s'inscrit en effet dans la continuité du Néolithique de Nubie et préfigure le Groupe $\mathrm{C}$ qui lui succédera. Très caractéristique à cet égard est la production céramique, qui reprend et perfectionne les formes et les décors de la plus belle poterie néolithique telle qu'elle apparaît par exemple à Kadrouka et qui semble vierge de toute influence égyptienne. Les formes sont simples et épurées, bols à fonds pointus ou arrondis, jarres dépourvues de cols et d'anses. Le décor est en revanche raffiné: opposition de couleurs entre bords noirs et panse rouge, surface parcourue de vaguelettes, peintures de motifs géométriques ou de défilés de bovidés. Ces récipients sont généralement polis à l'aide de galets taillés. Le sommet de l'art est atteint dans ces vases dits "en coquille d'œuf» (eggshell ware) où la pâte claire est d'une finesse extrême et décorée de figures géométriques de couleur rouge.

Contrairement à ce que laisserait croire le vocabulaire des spécialistes qui qualifient de «finale» ou «tardive» la dernière phase du Groupe A, cette période n'est en aucun cas marquée par un déclin, mais semble correspondre à l'apogée de cette civilisation de Nubie. Les habitats se multiplient, bien qu'ils soient localisés plus au sud que précédemment. Les agglomérations sont plus importantes et incluent, comme à Afya, de véritables maisons de pisé et de moellons de grès, aux murs couverts de mortier 

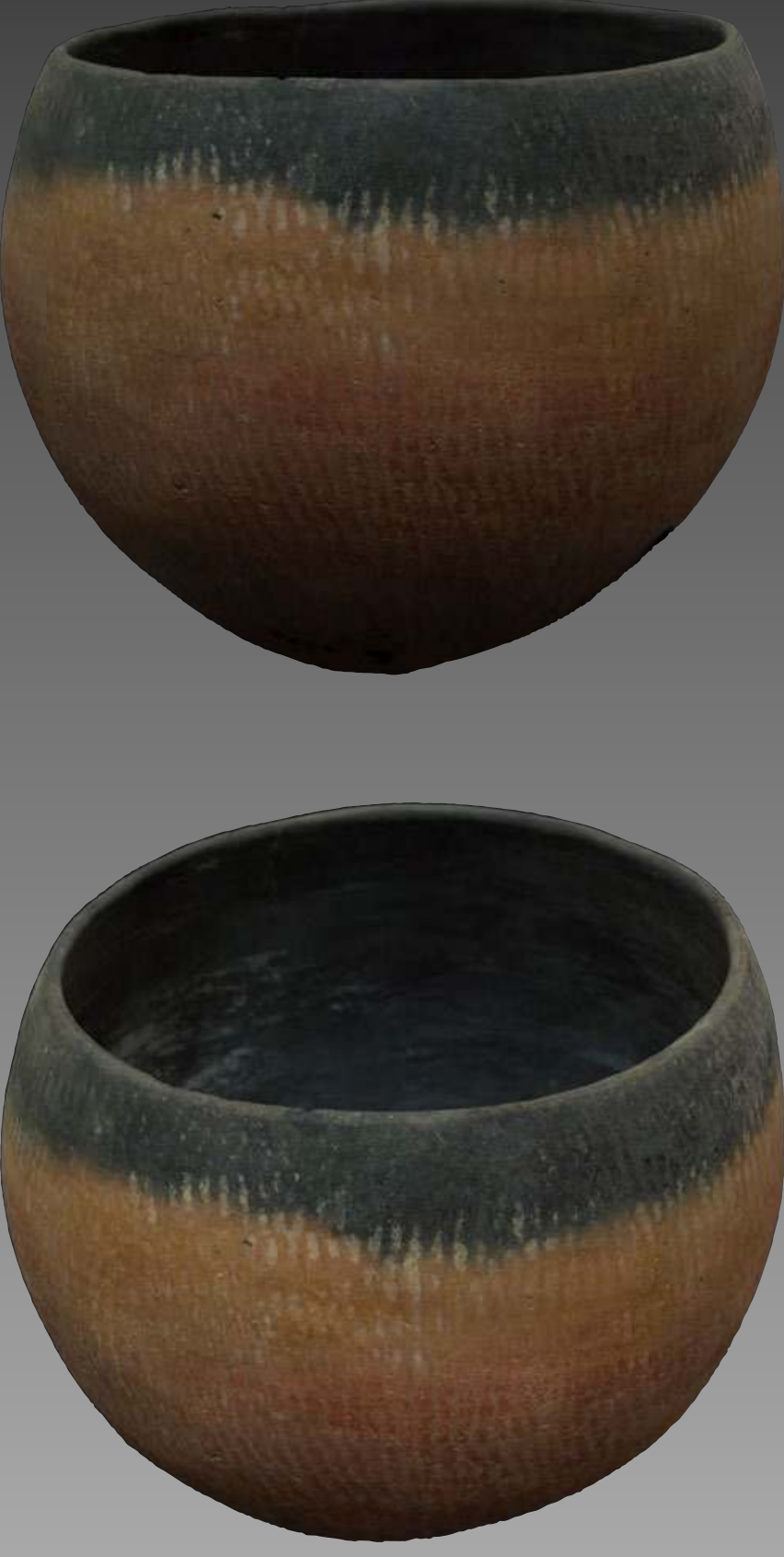

Vase rouge à bords noirs, Groupe A, Faras, musée national, Khartoum. 

et composées de plusieurs pièces. Des cimetières d'élite comportant de vastes tombes à Sayala et à Qustul laissent supposer que ces deux sites étaient les sièges de deux principautés contrôlant respectivement la zone centrale - entre première et deuxième cataracte - et celle située autour de la deuxième cataracte. Mais à part quelques indices comme la scène de l'encensoir de Qustul, qui figure un chef fort semblable aux premiers rois de Haute-Égypte, ou comme la présence de sceaux, qui témoignent de l'existence d'une administration locale, on manque d'éléments pour apprécier quelle était la situation politique sur le territoire du Groupe A.

La disparition du Groupe A s'est faite brutalement vers 2800 av. J.-C. Le coupable est tout désigné. C'est l'Égypte des premiers pharaons qui a vraisemblablement porté le coup fatal. Le crime est même signé. Sur les falaises qui surplombaient le Nil aux abords de la deuxième cataracte, au lieu-dit Gébel Cheikh-Suleiman, une scène symbolique maladroitement gravée, aujourd'hui perdue, permet d'avancer un premier nom. Elle figurait un gigantesque scorpion tenant un prisonnier entravé, à la tête coiffée d'une plume, autre caractéristique des guerriers nubiens. Or, l'un des derniers rois de Haute-Égypte durant la période prédynastique (dynastie 0, vers 3150 av. J.-C.), peu avant l'unification des Deux Terres, porte le nom de «Scorpion». En fait, deux souverains de Haute-Égypte sont connus sous ce nom, à Hiéraconpolis (égyptien Nekhen) et à Abydos, beaucoup plus au nord. Il est probable que le conquérant du Gébel CheikhSuleiman soit Scorpion II, roi d'Hiéraconpolis, où existait par ailleurs une communauté expatriée issue du Groupe A.

Une seconde scène du Gébel Cheikh-Suleiman, aux dimensions plus imposantes $(2,70 \times 0,80 \mathrm{~m})$, a été gravée dans le roc par les Égyptiens sous un roi de la I $\mathrm{I}^{\mathrm{e}}$ dynastie. Le bloc, détaché durant le sauvetage des monuments de Nubie en 1963-1964, a été remonté sous abri dans les jardins du musée de Khartoum. À gauche, on devine un faucon perché sur un serekh (façade de palais), le tout très érodé, mais caractéristique de la dénomination d'un pharaon aux époques archaïques. Une brève séquence écrite en hiéroglyphes et récemment identifiée par Pierre Tallet et Claire Somaglino figure à droite du serekh et se lit «jt». C'est le (court) nom de naissance du roi Djer, le troisième de la $\mathrm{I}^{\mathrm{e}}$ dynastie. Le serekh personnifié tient prisonnier un ennemi vaincu au moyen d'une corde enserrant ses deux bras attachés dans son dos. L'homme porte un arc, symbole de la Nubie, appelée "Terre de l'Arc» dès les plus anciens textes dynastiques. À droite, sous un vaisseau à haute proue, des cadavres disloqués baignent dans les eaux du Nil. En bas, au centre, figurent deux grandes croix cerclées, symboles de la cité (signe njw.t), surmontées d'hiéroglyphes difficilement identifiables mais qui doivent nommer les principautés conquises. 
Il ne fait pas de doute que nous avons ici les plus anciennes représentations connues d'une campagne militaire en Nubie entreprise par les souverains égyptiens. On sait par d'autres textes que le roi Aha de la I dynastie, prédécesseur de Djer, et Khasekhemouy, le dernier pharaon de la II dynastie (vers 2700 av. J.-C.), ont lancé des campagnes contre la "Terre de l'Arc». Mais sous le règne de ce dernier, le Groupe $\mathrm{A}$ avait déjà disparu et c'est sans doute plus au sud qu'il faut situer cette expédition. En effet, dès la deuxièmedynastie, la Basse-Nubie est conquise jusqu'à la deuxième cataracte et deux forteresses égyptiennes sont établies à Qoubban et à Bouhen. Seuls quelques rares vestiges attestent la présence d'une population locale pendant près de quatre siècles. Il semble que le Groupe A se soit dispersé, certains se réfugiant dans les zones encore verdoyantes des oasis du désert occidental, d'autres intégrant comme mercenaires les armées des pharaons de l'Ancien Empire.

\section{Le Pré-Kerma}

le Soudan

56

des origines

à la chute

du sultanat

Fung

Les adversaires du pharaon Khasekhemouy étaient très probablement les populations dites «Pré-Kerma» situées au sud de la deuxième cataracte et dont l'extension vers le sud (sans doute jusqu'à la quatrième cataracte) n'a cessé d'être repoussée au fil des découvertes archéologiques récentes. On suppose que cette culture s'est développée dès le milieu du quatrième millénaire, comme le Groupe $\mathrm{A}$, mais les attestations de la phase ancienne sont rares et discutées. C'est donc de la période entre 3000 et 2500 av. J.-C. que datent les sites connus. Pendant longtemps, les archéologues ont identifié les vestiges de cette culture comme une version méridionale du Groupe A, avec lequel elle présente en effet de nombreux points communs, notamment dans la céramique. C'est une découverte fortuite, suivie de longues et minutieuses fouilles, qui a permis d'établir l'identité de la culture Pré-Kerma.

Lors de travaux de dégagement opérés par la mission suisse, à la fin des années 1980, sur la nécropole orientale de la ville de Kerma, connue comme la capitale du premier État historique du Soudan entre 2450 et 1500 av. J.-C. et située au sud de la troisième cataracte (voir chapitre suivant, p. 59 sq.), l'archéologue suisse Charles Bonnet découvrit des trous de poteaux en grand nombre entre les fosses des tombes du Kerma moyen. La fouille fut confiée à un jeune préhistorien, futur directeur de la mission, Matthieu Honegger, qui allait à partir de ce travail, très ingrat au début, dégager une des premières villes africaines. Occupée aux environs de 3000 av. J.-C., elle s'étendait sur près de 10 ha et comprenait des dizaines de huttes circulaires, d'un diamètre approchant 4 mètres pour les habitations, des enclos pour le bétail, principalement des bovins à en juger par des empreintes de sabots encore 
visibles, ainsi que deux énigmatiques constructions rectangulaires, maintes fois reconstruites, qui pourraient avoir eu une fonction administrative ou religieuse. La cité, car on ne peut plus parler de village, était entourée d'une enceinte faite de hautes palissades en bois renforcées à la base de terre rapportée et qui s'ouvrait au nord par une porte encadrée de contreforts monumentaux faits de gros pieux rapprochés. Elle comportait plusieurs centaines de fosses-silos, dans lesquelles ont été parfois retrouvées des jarres de stockage qui avaient contenu des liquides. L'examen de dispositifs semblables sur l'île de Saï, à $170 \mathrm{~km}$ au nord, qui participait de la même culture, montre que des céréales originaires du Moyen-Orient et introduites en Nubie via l'Égypte, l'épeautre et l'orge, y étaient également conservées. Notre connaissance du Pré-Kerma reste toutefois très partielle parce que les deux sites principaux, Kerma et Saï, sont des lieux d'habitation. Seules quelques sépultures isolées appartenant à cette culture ont pour l'instant été mises au jour. Il est assez probable que le cimetière qui accueillait les défunts de l'agglomération PréKerma proprement dite a été détruit par le creusement des tombes ultérieures de la période Kerma. Nous devons nous estimer heureux qu'elles n'aient pas totalement oblitéré la ville protohistorique.

La céramique Pré-Kerma partage de nombreuses caractéristiques communes avec celle du Groupe A. On y trouve ainsi des formes ouvertes assez semblables, au corps rouge et au bord noir. Le polissage après cuisson y est aussi de rigueur. Des décorations en vaguelettes (rippled ware) sont souvent présentes mais elles ne concernent que la partie supérieure des objets. La poterie très fine du type "coquille d'œuf» est absente, mais les motifs au peigne qui l'ornent se retrouvent sur les vases Pré-Kerma. De façon générale, la céramique de cet horizon préfigure celle de la phase ancienne de la civilisation de Kerma.

Une des différences notables avec les sites de Basse-Nubie est l'absence quasi-totale de céramiques égyptiennes importées. Comme nous l'avons précédemment exposé, il est probable que le Groupe A s'était arrogé le monopole fort rentable des échanges directs avec l'Égypte. En revanche, on trouve sur le site principal Pré-Kerma des importations du Groupe A, notamment des poteries, des objets de cuivre (la métallurgie était inconnue plus au sud) et des palettes de quartzite. Bien que sans contact immédiat avec l'Égypte durant des siècles, la culture Pré-Kerma était donc un des maillons de la chaîne d'échanges qui fournissait au puissant voisin du nord les produits de l'intérieur de l'Afrique. Après la dispersion du Groupe A, il est probable que sa place dans le circuit fut reprise par les principautés Pré-Kerma désormais en contact direct avec les Égyptiens, comme l'atteste la présence de jarres importées du royaume pharaonique sur le site Pré-Kerma tardif de Saï. 
Contrairement à ce qui s'était passé en Basse-Nubie, il ne semble pas que la politique expansionniste de l'Égypte de l'Ancien Empire se soit poursuivie aux dépens des populations Pré-Kerma. Un seul épisode est relaté sur la Pierre de Palerme, une chronique des règnes précédents rédigée vers 2400 av. J.-C. sur un bloc de basalte conservé au musée de cette ville de Sicile: une expédition aurait été lancée sur la Nubie au temps du roi Snéfrou, père de Chéops, vers 2600 av. J.-C., aboutissant à la capture de 7000 prisonniers et de non moins de 200000 bovins. Ce dernier chiffre paraît grossièrement exagéré eu égard aux effectifs du bétail dans une région en voie de désertification et aux problèmes d'acheminement d'un tel troupeau, même en groupes séparés, jusqu'en Égypte. Quoi qu'il en soit, le royaume pharaonique maintint sa frontière à la deuxième cataracte et, à la différence du Groupe A, la culture Pré-Kerma continua d'exister, aboutissant vers 2450 av. J.-C. à la création du royaume de Kerma

le Soudan

\section{8}

des origines

à la chute

du sultanat

Fung
Pierre de Palerme,

grand fragment d'un monument

en basalte noir où figuraient

les annales royales. Musée

archéologique régional Salinas

de Palerme, Italie. L'ensemble

inclut six autres fragments:

cinq au musée du Caire

et un à l'University College

de Londres.

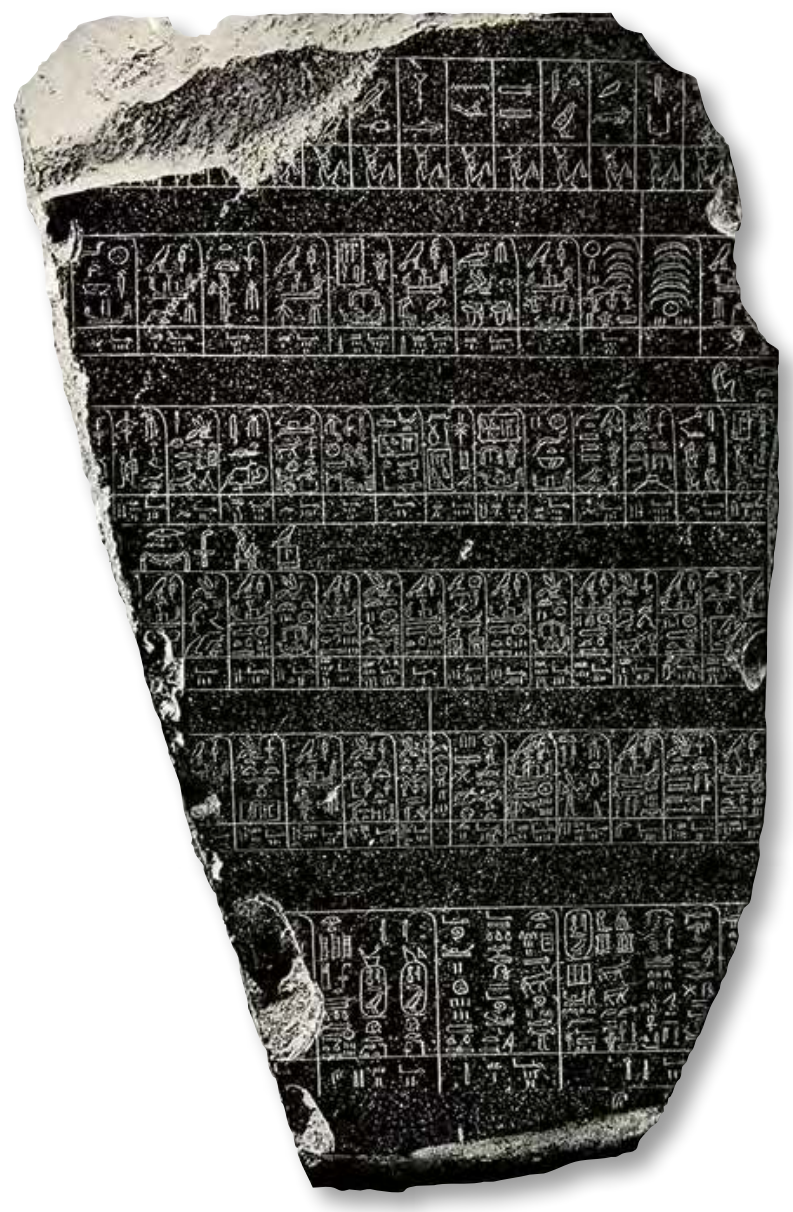

